\title{
Epidemiology of Cerebral Palsy in Adulthood: A Systematic Review and Meta-analysis of the Most Frequently Studied Outcomes
}

\author{
Marloes van Gorp, PhD, ${ }^{a, b}$ Sander R. Hilberink, PhD, ${ }^{a, c}$ Suzie Noten, MSc, ${ }^{a, b}$ \\ Joyce L. Benner, PhD, ${ }^{a, b}$ Henk J. Stam, MD, PhD, ${ }^{a}$ Wilma M.A. van der Slot, MD, PhD, ${ }^{b}$ \\ Marij E. Roebroeck, PhD ${ }^{a, b}$
}

From the ${ }^{a}$ Department of Rehabilitation Medicine, Erasmus MC University Medical Center, Rotterdam, The Netherlands; ${ }^{b}$ Rijndam Rehabilitation, Rotterdam, The Netherlands; and ${ }^{C}$ Research Centre Innovations in Care, Rotterdam University of Applied Sciences, Rotterdam, The Netherlands.

\begin{abstract}
Objective: To describe the epidemiology of health status, impairments, activities and participation in adults with cerebral palsy (CP).

Data Sources: Embase, MEDLINE, Web of Science, PsycINFO, Cumulative Index to Nursing and Allied Health, Cochrane, and Google Scholar were searched for 3 themes ("cerebral palsy," "adult," and "outcome assessment") in literature published between January 2000 and December 2018.

Study Selection: Full-article peer-reviewed English journal articles on descriptive, observational, or experimental studies describing the most studied outcomes in adults with CP ( $\mathrm{n} \geq 25$, age $\geq 18 \mathrm{y})$ were included. Studies were included in the analyses if frequently studied outcomes were described in at least 3 studies using similar methods of assessment.

Data Extraction: Data were extracted independently by 2 authors from 65 articles (total $\mathrm{N}=28,429$ ) using a standardized score sheet.

Data Synthesis: Meta-analyses revealed that overall, on average $65.1 \%$ (95\% confidence interval [CI], 55.1-74.5) of adults with CP experienced pain, 57.9\% (95\% CI, 51.1-64.6) were ambulant, 65.5\% (95\% CI, 61.2-69.7) had little or no limitation in manual ability, 18.2\% (95\% CI, 10.627.2) had tertiary education, $39.2 \%$ (95\% CI, 31.5;47.1) were employed, and $29.3 \%$ (95\% CI, 9.0-55.3) lived independently. In adults without intellectual disability, proportions of individuals who were ambulant (72.6\% [95\% CI, 58.8-84.5]) and lived independently (90.0\% [95\% CI, 83.894.9]) were higher ( $P=.014$ and $P<.01$, respectively). The Fatigue Severity Scale score was 4.1 (95\% CI, 3.8-4.4). Epilepsy (28.8\% [95\% CI, 20.1-38.4]) and asthma (28.3\% [95\% CI, 18.7-38.9]) were especially prevalent comorbidities.

Conclusions: The present systematic review and meta-analysis on the epidemiology of adults with CP provided state-of-the-art knowledge on the most frequently studied outcomes. On average, adults with CP are fatigued, and a majority experience pain, are ambulant, and have little or no difficulty with manual ability. On average, $40 \%$ are employed and $30 \%$ live independently. More uniformity in assessment and reports is advised to improve knowledge on epidemiology and gain insight in more outcomes.
\end{abstract}

Archives of Physical Medicine and Rehabilitation 2020;

(C) 2020 by the American Congress of Rehabilitation Medicine

Cerebral palsy $(\mathrm{CP})$ is an umbrella-term describing "a group of permanent disorders of the development of movement and posture, causing activity limitation, that are attributed to nonprogressive disturbances that occurred in the developing fetal or infant brain. The motor disorders of cerebral palsy are often

Supported by Rijndam Rehabilitation, Rotterdam, The Netherlands. Disclosures: none accompanied by disturbances of sensation, perception, cognition, communication and behavior, by epilepsy and by secondary musculoskeletal problems"1(p9) and it affects 2 to 2.5 per 1000 live births. ${ }^{1-4}$ Approximately three-fourths of persons with $\mathrm{CP}$ are adults (ie, 18 years or older). ${ }^{5}$

In the past decades, attention for adults with $\mathrm{CP}$ in rehabilitation practice and research increased. ${ }^{6}$ Aging with $\mathrm{CP}$ comes with several issues in health and functioning. Recently, several comorbidities were increased in adults with $\mathrm{CP}$, including asthma 
and hypertension. ${ }^{7,8}$ Pain and fatigue are common in adults with $\mathrm{CP},{ }^{9}$ and pain, mobility, and self-care deteriorate over time. ${ }^{10,11}$ In addition, young adults with $\mathrm{CP}$ are less often employed or live independently than young adults without $\mathrm{CP} .^{12,13}$ Moreover, activity limitations and difficulty in participation increase with aging. ${ }^{10,14}$

Common impairments and functional limitations in children with $\mathrm{CP}$ were previously studied in a systematic review, ${ }^{15}$ but systematic knowledge on adults with $\mathrm{CP}$ is scarce. Because differences were found in epidemiology between children and adults with $\mathrm{CP},{ }^{16}$ results cannot be extrapolated to the adult $\mathrm{CP}$ population. Insight into the prevalence of impairments and level of functioning in adults with $\mathrm{CP}$ would be helpful to guide rehabilitation follow-up programs. In addition, such insight would contribute to a better understanding of the effect of CP at adult age. Therefore, this review and meta-analysis aims to describe the health status, prevalence of impairments, and level of activities and participation of adults with $\mathrm{CP}$ using published literature. We focused on the most frequently studied outcomes in adults with $\mathrm{CP}$ from the literature, which were reported in a recently published review by Benner et al. ${ }^{6}$

\section{Methods}

\section{Search strategy}

The search strategy, which was developed in consultation with an information specialist, was used in 7 databases (Embase, MEDLINE, Web of Science, PsycINFO, Cumulative Index to Nursing and Allied Health, Cochrane, and Google Scholar) and consisted of 3 themes ("cerebral palsy," "adult," and "outcome assessment"). Key terms were mapped to controlled headings and expanded to include free text terms, tailored to the specific database. See Benner et al for the complete search strategy. ${ }^{6}$ Literature was searched from 2000 through 2018 because the search used in Benner et al was updated with publications from 2017 and 2018. After deduplication, all publications were screened for eligibility on title and abstract and subsequently full text by 2 independent reviewers (J.B., S.N. for publications in 2000-2016; M.vG., S.H. for 2017-2018), disagreements were discussed and resolved between the 2 reviewers. If disagreement remained this was discussed with a third reviewer (M.R.) to reach consensus.

\section{Eligibility criteria}

Studies were included if they met the following criteria: (1) They reported on the most frequently studied outcomes according to the systematic review of Benner et al. ${ }^{6}$ From this list of outcomes

\begin{tabular}{|rl|}
\hline List of abbreviations: \\
BMI body mass index \\
CI confidence interval \\
CP cerebral palsy \\
FSS & Fatigue Severity Scale \\
GMFCS & Gross Motor Function Classification System \\
ICF & International Classification of Functioning, \\
& Disability and Health \\
ID & intellectual disability \\
MACS & Manual Ability Classification System \\
SF-36 & Short Form-36 Health Survey \\
\hline
\end{tabular}

single-item outcomes (eg, pain) were selected if at least 10 studies provided information on this outcome; multi-item outcomes (eg, Fatigue Severity Scale [FSS]) were selected if at least 5 studies provided information. (2) At least 3 studies reported on an outcome using similar methods of assessment, enabling comparison and meta-analysis. (3) Study design was descriptive, observational, or experimental. Meta-analyses, reviews, case studies, qualitative studies, comments, and study protocols were excluded. (4) They were full-article peer-reviewed journal articles written in English. (5) They described individuals with CP only or in casecontrol design. (6) They described $\geq 25$ adults who were 18 years or older at the time of the first measurement or at follow-up. Studies describing both children and adults with CP were included when at least $50 \%$ of the sample were adults. (7) They reported on outcomes of functioning, excluding studies reporting on evaluations of services, for example, evaluation of transition services or complications and adverse events during or after surgery. (8) Study samples were population based or rehabilitation based, or samples addressed a substantial subgroup of individuals with $\mathrm{CP}$ (eg, Gross Motor Function Classification System [GMFCS] I-III, bilateral spastic $\mathrm{CP}$, dyskinetic $\mathrm{CP}$ ). Nonrepresentative samples that consisted of adults selected because of having specific impairments (eg, pain, fatigue, incontinence) or because of previous operations (eg, selective dorsal rhizotomy, constructive hip operations) were excluded. For intervention studies, only baseline observations were included. When outcomes were reported in multiple publications on the same study sample, the most recently observed outcome was included.

\section{Outcomes}

Frequently studied outcomes identified by Benner et al were grouped in line with the International Classification of Functioning, Disability, and Health (ICF) as health status, impairments, or activities and participation, with the first group encompassing outcomes that were not covered by the ICF or were linked to more than 1 component. ${ }^{6,17}$ These outcomes are depicted in the first column of Table 1. Health status outcomes addressed weight status (body mass index [BMI, calculated as weight in kilograms divided by height in meters squared], obesity), fat mass (waist circumference), comorbidities, and the domains of the Short Form-36 Health Survey, (SF-36) (scale range 0-100, with the physical health component score on a $\mathrm{T}$ score metric with a mean of 50 and SD of 10 for the US general population). ${ }^{78}$ Comorbidities included epilepsy, diabetes, hypertension, asthma, stroke, heart disease, and osteoarthritis. The impairments addressed pain (presence of any pain, including the outcomes pain in joints and pain in body part ${ }^{6}$ ), fatigue (assessed using the FSS, scale range $1-7)^{79}$ and mobility of joints (limited range of motion in knee or hip). Outcomes referring to the level of activities and participation were walking status (ambulant with or without assistive device as primary method of mobility in daily life), which included the outcomes walking or moving around using assistive devices and assistive devices for mobility ${ }^{6}$ ), fine hand use (Manual Ability Classification System [MACS] level I or II, manual ability), ${ }^{80}$ education status (attending or completing tertiary education according to the international standard classification of education; ie, higher education, college and university), ${ }^{81}$ employment status (having remunerative employment), living status (living independently), and activities and social roles, assessed using the Assessment of Life Habits questionnaire, Life-H (scale range $0-9) .{ }^{82}$ Although frequently studied according to Benner et al, ${ }^{6}$ we 
Table 1 Characteristics of included studies

\begin{tabular}{|c|c|c|c|c|c|c|}
\hline Author* & Country $^{\dagger}$ & $\mathrm{N}$ & ID $(\%)$ & GMFCS I-III (\%) & Age (y), Mean (Range) & $\%$ Male \\
\hline Ballester-Plané et al ${ }^{18}$ & Spain $^{\mathrm{a}}$ & 52 & Mixed & 56 & $25(7-62)$ & 54 \\
\hline Laporta-Hoyos et $\mathrm{al}^{19}$ & Spain $^{a}$ & 39 & Mixed & 64 & $21(6-62)$ & 51 \\
\hline Whitney et $\mathrm{al}^{20}$ & $U_{S A}^{b}$ & 1395 & Mixed & 54 & 18 to $>50$ & 48 \\
\hline Whitney et $\mathrm{al}^{8}$ & $U_{S A}^{b}$ & 452 & Mixed & 51 & $24(18-30)$ & 43 \\
\hline Cremer et $\mathrm{al}^{21}$ & $U S A^{b}$ & 435 & Mixed & 54 & $50(40-60)$ & 46 \\
\hline Cremer et al $a^{21}$ & $U_{S A}^{b}$ & 201 & Mixed & 55 & $48(40-60)$ & 100 \\
\hline Cremer et al $b^{21}$ & $U_{S A}^{b}$ & 234 & Mixed & 53 & $50(40-60)$ & 0 \\
\hline Ágústsson et $\mathrm{al}^{22}$ & Sweden ${ }^{c}$ & 830 & Mixed & 57 & $23(16-73)$ & 56 \\
\hline Alriksson-Schmidt et $\mathrm{al}^{23}$ & Sweden ${ }^{c}$ & 102 & Mixed & 72 & $21(18-24)$ & 62 \\
\hline Rodby-Bousquet et $\mathrm{al}^{24}$ & Sweden ${ }^{c}$ & 102 & Mixed & 72 & $21(19-23)$ & 62 \\
\hline van Gorp et $\mathrm{al} \mathrm{a}^{25}$ & The Netherlands ${ }^{d}$ & 67 & 31 & 67 & $25(21-27)$ & 67 \\
\hline van Gorp et al $b^{25}$ & The Netherlands ${ }^{d}$ & 54 & 0 & 82 & $32(29-34)$ & 54 \\
\hline van Meeteren et $\mathrm{al}^{26}$ & The Netherlands ${ }^{d}$ & 83 & 0 & $87^{\ddagger}$ & $20(18-22)$ & 59 \\
\hline Nieuwenhuijsen et $\mathrm{al}^{27}$ & The Netherlands ${ }^{d}$ & 87 & 0 & 90 & $20(18-22)$ & 59 \\
\hline Benner et $\mathrm{al}^{10}$ & The Netherlands ${ }^{\mathrm{e}}$ & 49 & 22 & 80 & $40(34-45)$ & 55 \\
\hline Benner et $\mathrm{al}^{12}$ & The Netherlands ${ }^{\mathrm{e}}$ & 49 & 22 & 80 & $40(34-45)$ & 55 \\
\hline van der Dussen et $\mathrm{al}^{28}$ & The Netherlands ${ }^{\mathrm{e}}$ & 80 & 28 & $71^{\S}$ & $21-31$ & 51 \\
\hline Kirk et al $\mathrm{a}^{29}$ & Denmark $^{f}$ & 22 & Mixed & 100 & $34(18-57)$ & 68 \\
\hline Kirk et al $b^{29}$ & Denmark $^{f}$ & 22 & Mixed & 100 & $37(18-59)$ & 55 \\
\hline McPhee et $\mathrm{al}^{30}$ & Canada $^{\mathrm{g}}$ & 42 & Mixed & 57 & $34(18-75)$ & 50 \\
\hline McPhee et $\mathrm{al}^{31}$ & Canada $^{g}$ & 42 & Mixed & 57 & $34(18-75)$ & 50 \\
\hline Slaman et al $a^{32}$ & The Netherlands ${ }^{\mathrm{h}}$ & 28 & 0 & 100 & $20(16-24)$ & 43 \\
\hline Slaman et al $b^{32}$ & The Netherlands ${ }^{h}$ & 29 & 0 & 98 & $20(16-24)$ & 52 \\
\hline Russchen et $\mathrm{al}^{33}$ & The Netherlands ${ }^{\mathrm{h}}$ & 56 & 0 & 100 & $20(16-24)$ & 48 \\
\hline Slaman et $\mathrm{al}^{34}$ & The Netherlands ${ }^{h}$ & 57 & 0 & 98 & $20(16-24)$ & 47 \\
\hline Ryan et $\mathrm{al}^{35}$ & Ireland & 55 & Mixed & 75 & $38(18-65)$ & 56 \\
\hline Morgan et $\mathrm{al}^{36}$ & Australia & 34 & 0 & 100 & $44(26-65)$ & 44 \\
\hline Morgan et $\mathrm{al}^{37}$ & Australia & 25 & 16 & 100 & $41(30-65)$ & 36 \\
\hline Reddihough et al $^{38}$ & Australia & 335 & 50 & 63 & $25(20-30)$ & 51 \\
\hline van der Slot et al $^{39}$ & The Netherlands ${ }^{i}$ & 43 & 0 & 95 & $37(25-45)$ & 63 \\
\hline van der Slot et al $a^{39}$ & The Netherlands ${ }^{i}$ & 27 & 0 & 95 & $37(25-45)$ & 100 \\
\hline van der Slot et al $b^{39}$ & The Netherlands ${ }^{i}$ & 16 & 0 & 95 & $37(25-45)$ & 0 \\
\hline van der Slot et $\mathrm{al}^{40}$ & The Netherlands ${ }^{i}$ & 56 & 0 & 93 & $36(25-45)$ & 63 \\
\hline van der Slot et al $^{41}$ & The Netherlands ${ }^{i}$ & 56 & 0 & 93 & $36(25-45)$ & 63 \\
\hline van der Slot et al $a^{41}$ & The Netherlands ${ }^{i}$ & 35 & 0 & 93 & $36(25-45)$ & 100 \\
\hline van der Slot et al $b^{41}$ & The Netherlands ${ }^{i}$ & 21 & 0 & 93 & $36(25-45)$ & 0 \\
\hline Opheim et $\mathrm{al}^{42}$ & Norway ${ }^{j}$ & 149 & 0 & 93 & $40(24-76)$ & 51 \\
\hline Opheim et $\mathrm{al}^{11}$ & Norway ${ }^{j}$ & 149 & 0 & 93 & $40(24-76)$ & 51 \\
\hline Jahnsen et $\mathrm{al}^{43}$ & Norway $^{j}$ & 406 & 0 & $78^{\S}$ & $34(18-72)$ & 51 \\
\hline Jahnsen et $\mathrm{al}^{44}$ & Norway ${ }^{j}$ & 406 & 0 & $78^{\S}$ & $34(18-72)$ & 51 \\
\hline Jahnsen et $\mathrm{al}^{45}$ & Norway ${ }^{j}$ & 766 & 0 & Mixed & $34(18-72)$ & 52 \\
\hline Maltais et $\mathrm{al}^{46}$ & Canada & 132 & Mixed & 60 & $28(20-41)$ & 50 \\
\hline Michelsen et $\mathrm{al}^{47}$ & Denmark $^{k}$ & 416 & 20 & $88^{\S}$ & $32(29-35)$ & 58 \\
\hline Michelsen et $\mathrm{al}^{48}$ & Denmark $^{k}$ & 819 & 20 & $84^{\S}$ & $29(21-35)$ & 58 \\
\hline Engel et $\mathrm{al}^{49}$ & USA & 100 & 0 & 18 & $38(19-71)$ & 55 \\
\hline Fortuna et $\mathrm{al}^{7}$ & USA & 229 & 54 & $55^{\S}$ & 18 to $>60$ & 59 \\
\hline Gillet et $\mathrm{al}^{50}$ & Australia & 33 & Mixed & $100^{\ddagger}$ & $25(15-51)$ & 55 \\
\hline Lundh et $\mathrm{al}^{51}$ & Sweden & 50 & Mixed & 100 & $32(22-67)$ & 54 \\
\hline Park et $\mathrm{al}^{52}$ & USA & 229 & $0^{\|}$ & 51 & $40(20-69)$ & 60 \\
\hline Peterson et $\mathrm{al}^{53}$ & USA & 2659 & Mixed & Mixed & Median (IQR): 36 (25-48) & 52 \\
\hline Sienko et $\mathrm{al}^{54}$ & USA & 97 & $41^{\pi}$ & 65 & $24(18-30)$ & 48 \\
\hline Smith et $\mathrm{al}^{55}$ & UK & 1705 & 21 & Mixed & $33 \pm 16$ & 53 \\
\hline Daunter et $\mathrm{al}^{56}$ & USA & 50 & $0^{\|}$ & 70 & $27(18-35)$ & 48 \\
\hline de Albuquerque Botura et $\mathrm{al}^{57}$ & Brazil & 93 & Mixed & 0 & $18-57$ & 56 \\
\hline Hayward et $a^{58}$ & USA & 375 & $24^{\pi}$ & 63 & $36(18-76)$ & 0 \\
\hline Park et $\mathrm{al}^{59}$ & Korea & 53 & Mixed & $63^{\ddagger}$ & $31 \pm 14$ & 62 \\
\hline Vukojevic et al ${ }^{60}$ & Bosnia and Herzegovina & 100 & 55 & Mixed & $18-58$ & 62 \\
\hline
\end{tabular}


Table 1 (continued)

\begin{tabular}{|c|c|c|c|c|c|c|}
\hline Author* & Country ${ }^{\dagger}$ & $\mathrm{N}$ & ID $(\%)$ & GMFCS I-III (\%) & Age (y), Mean (Range) & $\%$ Male \\
\hline Yildiz et $\mathrm{al}^{61}$ & Turkey & 117 & $26^{\#}$ & 74 & $25(18-62)$ & 55 \\
\hline Brunton et $\mathrm{al}^{62}$ & Canada & 111 & $0^{\|}$ & 78 & $19(14-31)$ & 50 \\
\hline Peterson et $\mathrm{al}^{63}$ & USA & 1015 & Mixed & Mixed & $58(57-60)$ & 66 \\
\hline Peterson et $\mathrm{al}^{64}$ & USA & 112 & Mixed & 52 & $34 \pm 13$ & 46 \\
\hline Huang et $\mathrm{al}^{65}$ & Taiwan & 279 & 28 & $50^{\S}$ & $26(20-40)$ & 61 \\
\hline Nedjad et $\mathrm{al}^{66}$ & Sweden & 156 & $62^{\pi}$ & $27^{\S}$ & $37(19-43)$ & 55 \\
\hline Mesterman et $\mathrm{al}^{67}$ & Israel & 95 & 35 & $83^{\S}$ & $23(18-30)$ & 61 \\
\hline Gaskin et $\mathrm{al}^{68}$ & Australia & 51 & 0 & 45 & $38(19-66)$ & 63 \\
\hline Andersson et al $a^{69}$ & Sweden & 13 & 0 & 100 & $36(26-58)$ & 64 \\
\hline Andersson et $a l b^{69}$ & Sweden & 12 & 0 & 100 & $36(26-58)$ & 64 \\
\hline Sandstrom et $\mathrm{al}^{70}$ & Sweden & 48 & $20^{\pi}$ & 71 & $33(20-?)$ & 48 \\
\hline Strauss et $\mathrm{al}^{71}$ & USA & 14,806 & Mixed & $62^{\S}$ & $20-85$ & 53 \\
\hline Andersson et $\mathrm{al}^{72}$ & Sweden & 221 & 0 & Mixed & $36(20-58)$ & 57 \\
\hline Bottos et $\mathrm{al}^{73}$ & Italy & 72 & 41 & $76^{\S}$ & $33(19-65)$ & 60 \\
\hline Furukawa et $\mathrm{al}^{74}$ & Japan & 81 & Mixed & $73^{\S}$ & $36(26-57)$ & 44 \\
\hline Hodgkinson et $\mathrm{al}^{75}$ & France & 234 & Mixed & 0 & $28(15-?)$ & 59 \\
\hline Maruishi et $\mathrm{al}^{76}$ & Japan & 256 & 43 & Mixed & $32(17-83)$ & 55 \\
\hline Murphy et $\mathrm{al}^{77}$ & USA & 101 & Mixed & Mixed & $43(19-74)$ & 52 \\
\hline
\end{tabular}

NOTE. Mixed: no exact proportion reported, also no in- or exclusion criteria regarding cognition or mobility.

Abbreviation: IQR, interquartile range.

* Letters $a$ or $b$ after the authors name (ie, Cremer et al a) indicate subsamples of 1 publication.

$\dagger$ Letters indicate publications on the same study sample in a country.

$¥$ Proportion of GMFCS level I and II.

$\S$ No GMFCS level reported; proportion walking with or without walking aid.

\| Those unable to complete questionnaires were excluded.

I Proportion proxy report.

\# Proportion illiterate, but individuals with severe cognitive impairments were excluded.

did not estimate overall results for the following outcomes because these were only reported in 1 or 2 included studies using a similar assessment method: spasticity, muscle power, hip displacement, gait pattern, speech, spinal deformities of thoracic, lumbar and sacral column, Barthel Index, ${ }^{83}$ FIM,${ }^{84}$ Gross Motor Function Measure, ${ }^{85}$ Functional Mobility Scale, ${ }^{86}$ and Japanese Orthopaedic Association Score. ${ }^{87}$

\section{Data extraction}

A standardized data extraction record sheet was used to collect study sample characteristics and outcomes. Sample characteristics included country, sample size, sex, age, proportion with intellectual disability (ID), and proportion with level of GMFCS I-III. ${ }^{88}$ Studies including any proportion of individuals with ID or those that did not mention exclusion based on intellectual function, suggesting individuals with ID could be part of the sample, were reported as mixed samples. Studies including only individuals without ID are further referred to as no ID samples. With respect to the outcomes, the method of assessment and the outcome (proportion [\%], or mean/median scores [SD/interquartile range]) were noted.

\section{Analysis}

Overall results with corresponding 95\% confidence intervals (CIs) were estimated using meta-analysis models. Overall mean proportions and means were estimated with a random-effects metaanalysis model using the DerSimonian and Laird estimator. ${ }^{89}$ The
Freeman-Tukey double arcsine transformation was used on proportions. ${ }^{90,91}$ Means were analyzed untransformed. Meta-analysis modeling was done using the metaprop and metamean functions of the meta package in $\mathrm{R} 3.2 .5$. $^{\mathrm{a}}$ The random-effects model takes the heterogeneity of samples into account. Statistical heterogeneity was quantified using the $I^{2}$ measure, which describes the amount of variation attributed to heterogeneity rather than sampling error across samples. ${ }^{92}$ Subgroup analyses of mixed and no ID samples were conducted, if multiple studies of mixed and no ID samples were available, for outcomes on activities and participation because ID is known to be strongly related to these outcomes. ${ }^{25,93}$ A random-effect $\mathrm{Q}$ test was used to test differences between mixed and no ID samples. Sensitivity analyses excluded specific subsamples of the population with $\mathrm{CP}$ from analyses if substantial deviations in the outcome could be explained by sample characteristics. These samples were for manual ability: a no ID sample ${ }^{25}$ and a sample with only individuals with dyskinetic subtype ${ }^{19}$ for epilepsy: a no ID sample ${ }^{52}$ and a sample with only individuals with GMFCS level IV and $\mathrm{V},{ }^{57}$ and for living situation: a young sample (mean age, 20y). ${ }^{27}$ Results of sensitivity analyses showed substantial influence of deviating samples, which were therefore excluded in the estimation of overall proportions and means; outcomes of the excluded studies were displayed in the forest plots.

\section{Results}

After deduplication, the initial search revealed 6662 publications (fig 1). After screening by title and abstract, 810 full-text articles 


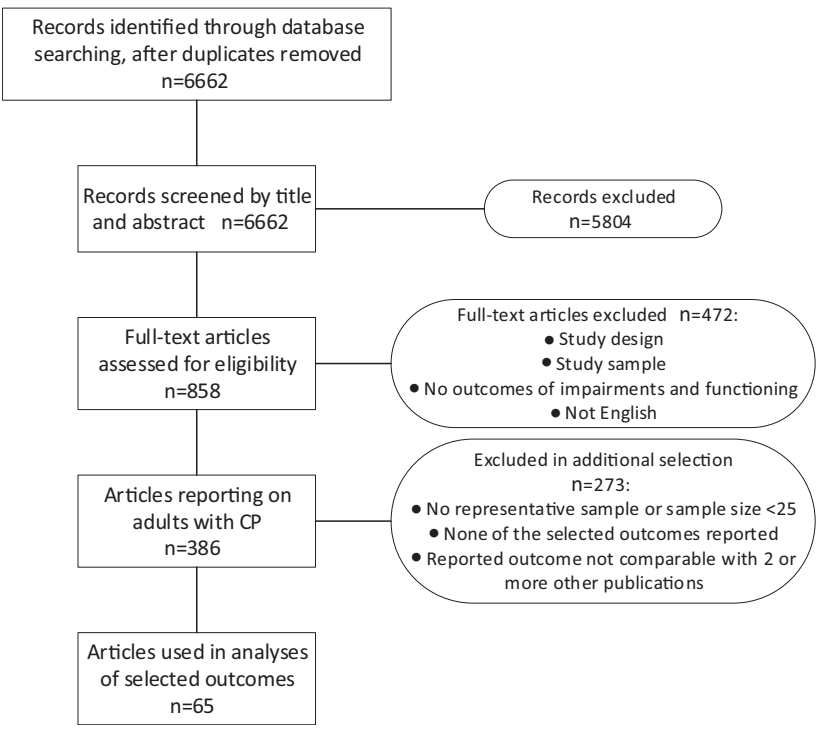

Fig 1 Flow diagram of study selection process.

were assessed for eligibility. Finally, 65 articles (total $\mathrm{N}=28,429$ ) were included in the meta-analyses, meaning these reported 1 or more of the selected outcomes comparable to at least 2 other studies. Table 1 displays the characteristics of the studies used in the meta-analyses. Of the samples, $73 \%$ were mixed and $27 \%$ were no ID. The mean age of the study samples was 32 years, samples consisted on average of $68 \%$ individuals with GMFCS level I-III and 53\% were male. Table 2 shows the overall proportion and/or mean for each of the outcomes, and fig 2 and supplemental appendix S1 (available online only at http://www. archives-pmr.org/) show the forest plots of these analyses. The level of heterogeneity $\left(I^{2}\right)$ was substantial $(>75 \%)$ for most of the analyses, reflecting considerable variation in results between studies (see fig 2, supplemental appendix S1).

\section{Health status}

Mean overall BMI was 25.1 (95\% CI, 23.8-26.5), and 22.6\% (95\% CI, 14.7-31.5) of individuals with CP were obese (BMI $>30$ ). Epilepsy (28.8\% [95\% CI, 20.0-38.4]), asthma (28.3\% [95\% CI, 18.7-38.9]), and hypertension (21.6\% [95\% CI: 15.6; 28.4]) were the most prevalent comorbidities. The overall estimated mean SF36 physical component score was 44.6 (95\% CI, 40.7-48.5).

\section{Impairments}

Overall presence of pain was estimated at $65.1 \%$ (95\% CI, 55.174.5). For fatigue, the overall estimated mean FSS score was 4.1 (95\% CI, 3.8-4.4). Limitations in knee and hip mobility were estimated to be present in $39.5 \%$ (95\% CI, 21.1-59.5) and $33.4 \%$ (95\% CI, 15.1-54.6) of adults with CP, respectively.

\section{Level of activities and participation}

A majority of adults with $\mathrm{CP}$ in mixed samples were estimated to be ambulatory $(57.9 \%$ [95\% CI, 51.1-64.6]) and to have little or no limitation in manual ability (MACS level I or II, 65.5\% [95\% CI, 61.2-69.7]). The proportion of ambulatory individuals seemed higher in the 2 no ID samples $(72.6 \%$ [95\% CI, 58.8-84.5], Q: $3.60, P=.058)$. Analyses on additional outcomes of those ambulatory included all samples, regardless of ID. Among ambulatory individuals, 31.9\% (95\% CI, 22.2-42.4) used an assistive device, and $56.2 \%$ (95\% CI, 37.0-74.5) had reported to perceive a decline in walking function or capacity over time. The overall mean results on the 6-minute walk test of ambulatory adults with CP was $387.9 \mathrm{~m}$ (95\% CI, 328.5-447.3).

Reports of attendance of tertiary education were remarkably similar between mixed samples and no ID samples (Q: 1.03, $P=0.31$, overall result: $18.2 \%$ [95\% CI, 10.6-27.2]). The mean estimated proportion of adults with $\mathrm{CP}$ with remunerative employment tended to be lower in mixed samples $(39.2 \%$ [95\% CI, 31.5-47.1]) than in no ID samples (56.0\% [95\% CI, 31.7-78.9], Q: $1.64, P=.200)$. A large difference (Q: $22.11, P<0.01$ ) was found in the proportions living independently between mixed samples $(29.3 \%$ [95\% CI, 9.0; 55.3]) and no ID samples $(90.0 \%$ [95\% CI, 83.8; 94.8]). Only used in no ID samples, the overall estimated mean Life-H activities score was 8.0 (95\% CI, 7.5-8.4), and the social roles score was 8.2 (95\% CI, 7.9-8.4).

\section{Discussion}

This systematic review and meta-analysis estimated overall health status, and rates of impairments, activities, and participation of adults with CP for the most studied outcomes in the available literature according to a recent systematic review by Benner et al. ${ }^{6}$ This provides state-of-the-art knowledge for this population on a range of topics, such as pain, walking status, living situation, and comorbidities based on large accumulated samples combined from studies across the globe.

\section{Health status}

Body composition and comorbidities that are known to be associated with lifestyle, such as obesity, hypertension, and diabetes, vary strongly across regions and age. The overall proportions estimated in the present review are therefore difficult to compare with general population data irrespective of age. Still, the overall estimates that we provided for adults with $\mathrm{CP}$ provide a robust indication of the occurrence of several comorbidities in the $\mathrm{CP}$ adult population. Epilepsy is a known comorbidity of CP and is included in its definition. ${ }^{1}$ The overall occurrence of $28.8 \%$ is similar to that reported in a previous review of adults with $\mathrm{CP}$ and the more recent review in children with $\mathrm{CP}^{2,15}$ In addition, the overall estimated occurrence of asthma in adults with CP $(28.3 \%)$ exceeds prevalence rates that were reported across the globe in general populations (ranging from $1.0 \%-21.5 \%),{ }^{94}$ suggesting that asthma may be a common comorbidity in $\mathrm{CP}$.

\section{Impairments}

Pain is the most frequently studied outcome in adults with $\mathrm{CP}{ }^{6}$ The estimated occurrence of pain $(65 \%)$ is in line with another recent review in adults with $\mathrm{CP}$ focusing on pain using individual patient data $(70 \% ; 95 \% \mathrm{CI}, 62-78)^{95}$ and seems to be more prevalent compared with the general US population $(56 \%) .{ }^{96}$ For fatigue we estimated an overall score on the FSS over 4.0, which is often used as a cutoff score indicating fatigue, implying that on average adults with $\mathrm{CP}$ experience fatigue. ${ }^{97} \mathrm{~A}$ Swiss study found a similar mean score for patients with a recent stroke and a lower mean score (3.0) for healthy subjects without $\mathrm{CP} .{ }^{97}$ Prevention and 
Table 2 Meta-analyses results

\begin{tabular}{|c|c|c|c|}
\hline Outcome & Studies (n) (Reference nos.) & $\begin{array}{l}\text { Cases in } \\
\text { Analysis (N) }\end{array}$ & $\begin{array}{l}\text { Overall Proportion } \\
\text { or Mean }(95 \% \mathrm{CI})\end{array}$ \\
\hline \multicolumn{4}{|l|}{ Health status } \\
\hline \multicolumn{4}{|l|}{ Body composition } \\
\hline Waist circumference (mean, in $\mathrm{cm}$ ) & $5\left(\left(^{31,34,35,39,64}\right)\right.$ & 266 & $84.0(82.2-85.7)$ \\
\hline BMI (mean) & $6(21,31,33,35,39,64)$ & 743 & $25.1(23.8-26.5)$ \\
\hline Obese $(\% \quad B M I \geq 30)$ & $7\left({ }^{7,21,30,35,39,59,64}\right)$ & 968 & $22.6 \%(14.7-31.5)$ \\
\hline \multicolumn{4}{|l|}{ Comorbidities (\%) } \\
\hline Epilepsy & $6\left({ }^{7,10,18,55,60,73}\right)$ & 2189 & $28.8 \%(20.0-38.4)$ \\
\hline Diabetes & $7(7,8,30,39,52,53,55,63)$ & 6594 & $6.7 \%(3.8-10.3)$ \\
\hline Hypertension & $8(7,8,30,39,52,53,59,63)$ & 4646 & $21.6 \%(15.6-28.4)$ \\
\hline Asthma & $4\left({ }^{7,8,21,63}\right)$ & 2076 & $28.3 \%(18.7-38.9)$ \\
\hline Stroke & $3\left({ }^{8,21,63}\right)$ & 1847 & $2.0 \%(0.0-6.8)$ \\
\hline Heart disease & $3\left({ }^{55,63,73}\right)$ & 2792 & $9.5 \%(5.1-15.0)$ \\
\hline Osteoarthritis & $3\left({ }^{8,21,55}\right)$ & 2537 & $11.4 \%(2.0-26.9)$ \\
\hline \multicolumn{4}{|l|}{ SF-36 (mean) } \\
\hline \multicolumn{4}{|l|}{ Samples without ID } \\
\hline Physical component & $3\left({ }^{36,41,42}\right)$ & 239 & $44.6(40.7-48.5)$ \\
\hline Physical function & $4\left(\left(^{32,36,41,68}\right)\right.$ & 197 & $53.9(34.0-73.7)$ \\
\hline Role physical & $4\left(\left(^{32,36,41,68}\right)\right.$ & 197 & $72.6(67.7-77.6)$ \\
\hline Role emotional & $4\left(\left(^{32,36,41,68}\right)\right.$ & 197 & $82.7(77.9-87.5)$ \\
\hline Vitality & $4\left({ }^{32,36,41,68}\right)$ & 197 & $56.9(53.3-60.5)$ \\
\hline Mental health & $4\left({ }^{32,36,41,68}\right)$ & 197 & $73.8(71.6-76.0)$ \\
\hline Social functioning & $4\left({ }^{32,36,41,68}\right)$ & 197 & $80.6(76.5-84.6)$ \\
\hline Bodily pain & $5\left({ }^{32,36,41,44,68}\right)$ & 599 & $70.3(63.5-77.2)$ \\
\hline General health & $4\left({ }^{32,36,41,68}\right)$ & 197 & $70.6(67.2-73.9)$ \\
\hline \multicolumn{4}{|l|}{ Impairments } \\
\hline \multicolumn{4}{|l|}{ Pain (\%) } \\
\hline Presence of any pain & $16\left({ }^{10,24,40,44,49,51,54,56,57,59,62,66,70,72,74,76}\right)$ & 1836 & $65.1 \%(55.1-74.5)$ \\
\hline \multicolumn{4}{|l|}{ Fatigue (mean) } \\
\hline Fatigue Severity Scale & $5\left({ }^{11,33,40,51,56}\right)$ & 352 & $4.1(3.8-4.4)$ \\
\hline \multicolumn{4}{|l|}{ Mobility of joints (\%) } \\
\hline Limited knee mobility & $3\left({ }^{22,51,70}\right)$ & 928 & $39.5 \%(21.1-59.5)$ \\
\hline Limited hip mobility & $3(22,51,70)$ & 928 & $33.4 \%(15.1-54.6)$ \\
\hline \multicolumn{4}{|l|}{ Activities and participation } \\
\hline \multicolumn{4}{|l|}{ Walking status } \\
\hline \multicolumn{4}{|l|}{ Ambulatory (\%) - subgroup analysis: } \\
\hline Mixed samples & $9\left({ }^{7,10,46,65,67,71,73,74,77}\right)$ & 15839 & $57.9 \%(51.1-64.6)$ \\
\hline Samples without ID & $2\left({ }^{43,72}\right)$ & 627 & $72.6 \%(58.8-84.5)$ \\
\hline $\begin{array}{l}\text { Ambulatory with assistive devices of } \\
\text { those ambulatory }(\%)\end{array}$ & $5\left({ }^{43,65,72-74}\right)$ & 689 & $31.9 \%(22.2-42.4)$ \\
\hline Perceived walking decline (\%) & $4\left({ }^{11,36,37,46}\right)$ & 293 & $56.2 \%(37.0-74.5)$ \\
\hline 6MWT (mean, in $\mathrm{m}$ ) & $4\left({ }^{29,37,50,69}\right)$ & 127 & $387.9(328.5-447.3)$ \\
\hline \multicolumn{4}{|l|}{ Manual ability (\%) } \\
\hline $\begin{array}{l}\text { No or little limitation (MACS } \\
\text { level I or II) }\end{array}$ & $3\left({ }^{23,25,58}\right)$ & 485 & $65.4 \%(61.1-69.6)$ \\
\hline \multicolumn{4}{|l|}{ Education (\%) } \\
\hline Tertiary education (all samples) & $8\left({ }^{28,38,45,48,65,72,73,77}\right)$ & 2635 & $18.2 \%(10.6-27.2)$ \\
\hline \multicolumn{4}{|l|}{ Employment $(\%)$} \\
\hline \multicolumn{4}{|l|}{$\begin{array}{l}\text { Remunerative employment - } \\
\text { subgroup analysis: }\end{array}$} \\
\hline Mixed samples & $9\left({ }^{12,23,38,48,65,67,73,74,77}\right)$ & 1845 & $39.2 \%(31.5-47.1)$ \\
\hline Samples without ID & $4\left({ }^{11,27,41,72}\right)$ & 437 & $56.0 \%(31.7-78.9)$ \\
\hline \multicolumn{4}{|l|}{ Living status $(\%)$} \\
\hline \multicolumn{4}{|l|}{$\begin{array}{l}\text { Living independently - subgroup } \\
\text { analysis: }\end{array}$} \\
\hline Mixed samples & $7\left({ }^{23,38,47,67,71,73,77}\right)$ & 15927 & $29.3 \%(9.0-55.3)$ \\
\hline Samples without ID & $3\left({ }^{11,41,72}\right)$ & 426 & $90.0 \%(83.8-94.8)$ \\
\hline
\end{tabular}


Table 2 (continued)

\begin{tabular}{|c|c|c|c|}
\hline Outcome & Studies (n) (Reference nos.) & $\begin{array}{l}\text { Cases in } \\
\text { Analysis (N) }\end{array}$ & $\begin{array}{l}\text { Overall Proportion } \\
\text { or Mean }(95 \% \text { CI) }\end{array}$ \\
\hline \multicolumn{4}{|l|}{$\begin{array}{l}\text { Activities and social roles } \\
\text { (mean score Life-H) }\end{array}$} \\
\hline \multicolumn{4}{|l|}{ Activities domain } \\
\hline Samples without ID & $3\left({ }^{26,32,41}\right)$ & 198 & $8.0(7.5-8.4)$ \\
\hline \multicolumn{4}{|l|}{ Social roles domain } \\
\hline Samples without ID & $3\left({ }^{26,32,41}\right)$ & 198 & $8.2(7.9-8.4)$ \\
\hline
\end{tabular}

treatment of pain and fatigue are high priorities on a recent patient-centered research agenda ${ }^{98}$ because literature on pain and fatigue management and lifestyle strategies for this population is scarce. ${ }^{32,99,100}$ Using insights from previous studies as a starting point, such as discussing pain and fatigue management with adults with $\mathrm{CP}$ and applying a multidimensional lifestyle intervention program, future studies should aim to determine the effectiveness of interventions reducing pain and fatigue.

We found that 1 in 3 adults with CP experience limited knee and hip mobility. However, variation of these proportions were very large, and few population-based studies were available that reported joint mobility in adults with CP. Systematic knowledge of joint mobility seems to be under-reported in current literature. Similarly, other impairments that frequently occur in individuals with $\mathrm{CP}$, such as spasticity, hip displacement and spinal deformities, were not often reported on in population-representative samples or lacked standardized assessments. ${ }^{2,15,22}$

\section{Activities and participation}

A majority of adults with CP were ambulatory (58\%) and experienced little or no difficulty with manual ability $(65 \%)$. However, the proportion of ambulant individuals is lower than that previously reported in children with $\mathrm{CP}(72 \%) .^{15}$ This is likely explained by a decline in walking function as individuals with $\mathrm{CP}$ get older, which we found to be experienced by half of the ambulant adults with CP. The proportion of adults with CP who experienced little or no limitation with manual ability ( $65 \%)$ was very close to that reported in a population-based study of children with $\mathrm{CP}(64 \%) .{ }^{101}$ This suggests that although walking ability declines in individuals with CP, manual ability remains relatively stable in adulthood.

The overall proportions of adults with tertiary education (18\%), having remunerative employment (39\%), and living independently $(29 \%)$ seem low but are very difficult to compare with reference values because of regional differences and agespecific participation rates, for example. Additionally, the variation between CP samples is also large, as shown by large statistical heterogeneity (92\%-99\%), a very large 95\% CI for living situation, and substantially higher proportions of participation in samples without adults with ID. Importantly, in individuals without ID, proportions of living independently were very high (90\%). Surprisingly, regarding tertiary education and remunerative employment there were no significant differences between mixed samples and samples without ID, which may indicate that adults with CP without ID may still be disadvantaged in these life areas. Although the sample from the study of Murphy et al used in the meta-analyses of the outcomes walking, education, employment status, and living situation was not reported to be selected based on intellectual disability (ie, it was considered a mixed sample), the results were deviant. ${ }^{77}$ This might be explained by a large proportion of the sample classified as dyskinetic (50\%), which usually represent smaller parts of the population. ${ }^{2}$ Individuals with dyskinetic CP may have different levels of participation than those with spastic $\mathrm{CP}$, causing results of this sample to differ.

Overall scores on daily activities and social roles (Life-H) were close to the cutoff for experiencing difficulty. ${ }^{102,103}$ These scores are only estimated based on Dutch samples without ID, which may limit generalization. Similarly, overall domain scores for physical functioning and role limitations because of physical health (SF-36) were low compared with reference values reflecting limitations in activities and participation. ${ }^{104}$

\section{Heterogeneity in samples and studies}

The high level of statistical heterogeneity, indicating substantial variation between study results, and the wide confidence intervals in some of the analyses may partly be explained by sample differences. These differences in samples reflect the heterogeneity of the population with $\mathrm{CP}$, of which the definition is an umbrella term. ${ }^{1}$ Previous studies found associations between CP severity and many of the described outcomes. ${ }^{8,12,14,95}$ Because of the available information, we were unable to disentangle differences in outcomes for other determinants (eg, level of motor function, age, or region) than mixed samples and samples without ID. We recommend future studies to systematically report overall results for subgroups of adults with CP to improve clinical interpretation. Moreover, we strongly recommend to further standardize assessments in future research and clinical care for adults with CP. Examples of presently ongoing standardization in this field are improving the uniformity of registries ${ }^{105,106}$ and extending them into the adult population, ${ }^{23}$ developing core outcome sets for specific outcomes, ${ }^{107}$ and creating an overarching ICF core set for adults with $\mathrm{CP}{ }^{6}$

\section{Study limitations}

The literature search we conducted was very comprehensive, with 386 English-language publications on adults with $\mathrm{CP}$ reporting outcomes of functioning identified by screening more than 6000 records from the database searches. However, some publication bias may be present because we omitted non-English language publications, which comprised less than $10 \%$ of the eligible publications. Another source of publication bias might be inconclusive trials that were not published. We expect this source of publication bias to be negligible because the outcomes we studied were noncomparative, ${ }^{108}$ and intervention trials in adults with $\mathrm{CP}$ are very 


\section{A}

Study

Population $=$ Mixed

Strauss et al ${ }^{71} 2004$

Huang 2013

Fortuna 2018

Maltais 2010

Murphy 2000

Mesterman 2010

Furukawa 2001

Bottos 2001

Benner 20171

Random effects model

Heterogeneity: $I^{2}=90 \%, \tau^{2}=0.0087, P<.01$

Population $=$ No ID

Jahnsen 20041

Andersson 2001

Random effects model

Heterogeneity: $I^{2}=92 \%, \tau^{2}=0.0101, P<.01$

Random effects model

Heterogeneity: $I^{2}=92 \%, \tau^{2}=0.0087, P<.01$

Residual heterogeneity: $I^{2}=90 \%, P<.01$

B

Study

Hayward 2017

Alriksson-Schmidt 2014

van Gorp 2018 a

Laporta-Hoyos 2018

van Gorp 2018 b

Random effects model

Heterogeneity: $I^{2}=0 \%, \tau^{2}=0, P=.51$

C

Study

Population $=$ Mixed

Michelsen 2005

Reddihough 2013

Huang 2013

Murphy 2000

van der Dussen 2001

Bottos 2001

Random effects model

Heterogeneity: $I^{2}=97 \%, \tau^{2}=0.0396, P<.01$

Population $=$ No ID

Jahnsen 2002

Andersson 2001

Random effects model

Heterogeneity: $I^{2}=0 \%, \tau^{2}=0, P=.79$

Random effects model

Heterogeneity: $I^{2}=96 \%, \tau^{2}=0.0224, P<.01$

Residual heterogeneity: $I^{2}=97 \%, P<.01$

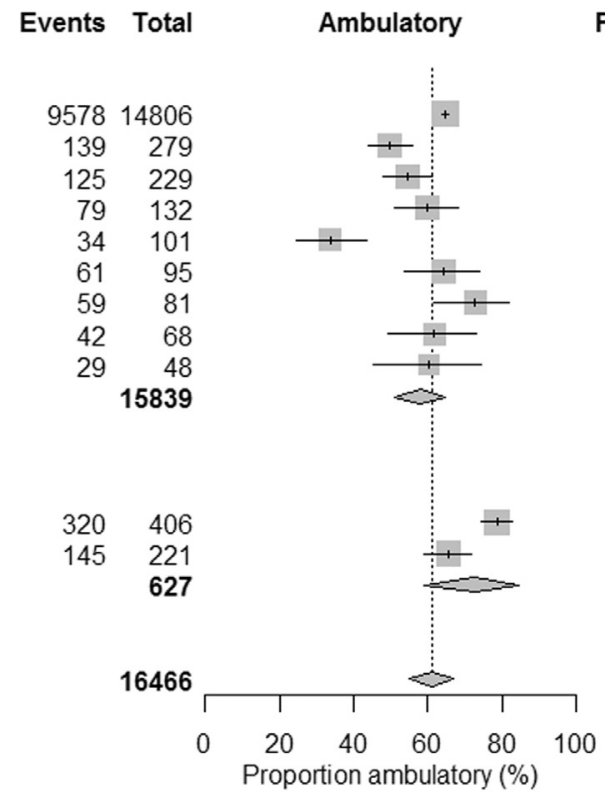

Proportion (\%) $\quad 95 \% \mathrm{Cl}$ Weight

$64.7[63.9-65.5] \quad 11.0 \%$

$49.8[43.8-55.8] \quad 10.0 \%$

$54.6[47.9-61.2] \quad 9.8 \%$

$59.8[51.0-68.3] \quad 9.1 \%$

33.7 [24.6-43.8] $8.6 \%$

$64.2[53.7-73.8] \quad 8.5 \%$

$72.8[61.8-82.1] \quad 8.2 \%$

$61.8[49.2-73.3] \quad 7.8 \%$

60.4 [45.3-74.2] $6.9 \%$

57.9 [51.1-64.6] $79.9 \%$

$78.8[74.5-82.7] \quad 10.3 \%$ $65.6[58.9-71.9] \quad 9.8 \%$

$72.6[58.8-84.5] \quad 20.1 \%$

$61.0[54.9-66.9] 100.0 \%$
Events Total

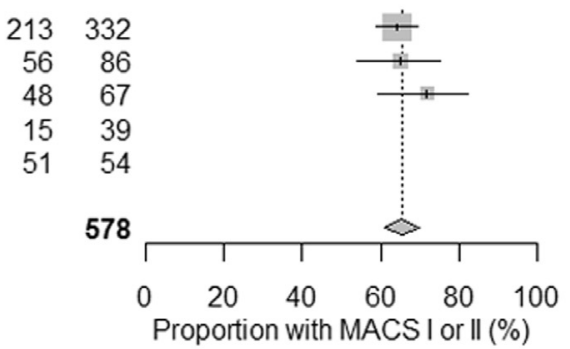

Proportion (\%) $\quad 95 \% \mathrm{Cl}$ Weight

$64.2[58.7-69.3] \quad 68.3 \%$

$65.1[54.1-75.1] \quad 17.8 \%$

$71.6[59.3-82.0] 13.9 \%$

38.5 [23.4-55.4] $0.0 \%$

$94.4[84.6-98.8] \quad 0.0 \%$

$65.5[61.2-69.7] 100.0 \%$
Events Total

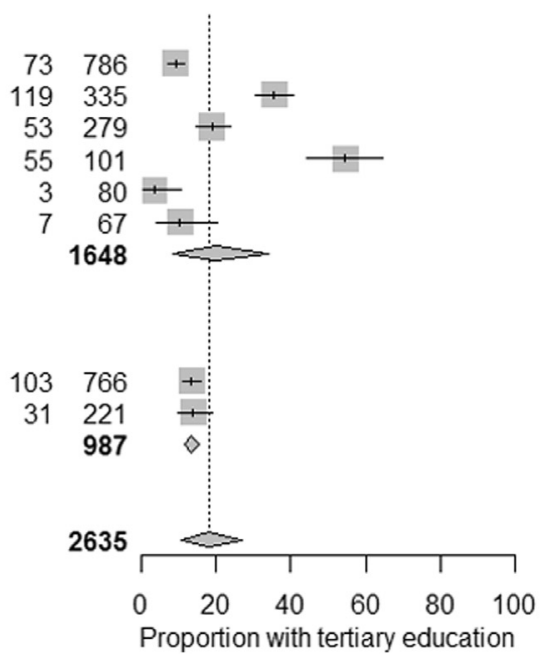

Proportion (\%) $\quad 95 \% \mathrm{Cl}$ Weight
$13.4[11.1-16.1] \quad 13.2 \%$

$14.0 \quad[9.7-19.3] \quad 12.7 \%$

$13.5[11.5-15.8] 25.9 \%$

$18.2[10.6-27.2] 100.0 \%$

Fig 2 Forest plots of main outcomes of activities and participation. (A) Walking status; (B) manual ability; (C) education status; (D) employment status; (E) living situation. 
$\mathbf{D}_{\text {Study }}$

\section{Population $=$ Mixed}

Michelsen 2005

Reddihough 2013

Huang 2013

Murphy 2000

Mesterman 2010

Furukawa 2001

Alriksson-Schmidt 2014

Bottos 2001

Benner 20172

Random effects model

Heterogeneity: $I^{2}=90 \%, \tau^{2}=0.0124, P<.01$

Population $=$ No ID

Andersson 2001

Opheim 2009

van der Slot 2010

Nieuwenhuijsen 2009

Random effects model

Heterogeneity: $I^{2}=96 \%, \tau^{2}=0.0571, P<.01$

Random effects model

Heterogeneity: $I^{2}=94 \%, \tau^{2}=0.0251, P<.01$

Residual heterogeneity: $I^{2}=92 \%, P<.01$

Etudy

Population $=$ Mixed

Strauss et al ${ }^{71} 2004$

Michelsen 2006

Reddihough 2013

Alriksson-Schmidt 2014

Murphy 2000

Mesterman 2010

Bottos 2001

Random effects model

Heterogeneity: $I^{2}=99 \%, \tau^{2}=0.1249, P<.01$

Population $=$ No ID

Andersson 2001

Opheim 2009

Nieuwenhuijsen 2009

van der Slot 2010

Random effects model

Heterogeneity: $I^{2}=68 \%, \tau^{2}=0.0042, P=.04$

Random effects model

Heterogeneity: $I^{2}=100 \%, \tau^{2}=0.2182, P=0$

Residual heterogeneity: $I^{2}=99 \%, P<.01$
Events Total

Proportion (\%)

$95 \% \mathrm{Cl}$ Weight

$\begin{array}{rr}279 & 778 \\ 121 & 335 \\ 64 & 279 \\ 71 & 101 \\ 36 & 95 \\ 36 & 81 \\ 20 & 65 \\ 21 & 62 \\ 22 & 49 \\ & \mathbf{1 8 4 5}\end{array}$

35.9 [32.5-39.3] $8.4 \%$

36.1 [31.0-41.5] $8.3 \%$

22.9 [18.1-28.3] $8.2 \%$

$70.3[60.4-79.0] \quad 7.8 \%$

37.9 [28.1-48.4] $7.7 \%$

44.4 [33.4-55.9] $7.6 \%$

$30.8[19.9-43.4] \quad 7.4 \%$

33.9 [22.3-47.0] $7.4 \%$

44.9 [30.7-59.8] $7.1 \%$

$39.2[31.5-47.1] \quad 70.0 \%$

$71.6[64.8-77.6] \quad 8.1 \%$

29.7 [22.4-37.8] $8.0 \%$

$70.4[56.4-82.0] \quad 7.2 \%$

$50.0[32.4-67.6] \quad 6.6 \%$

$55.5[31.5-78.3] \quad 30.0 \%$

$44.1[35.2-53.3] 100.0 \%$

2282

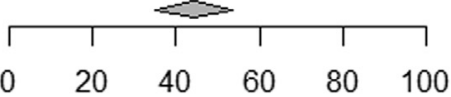

Proportion with remunerative employment (\%)

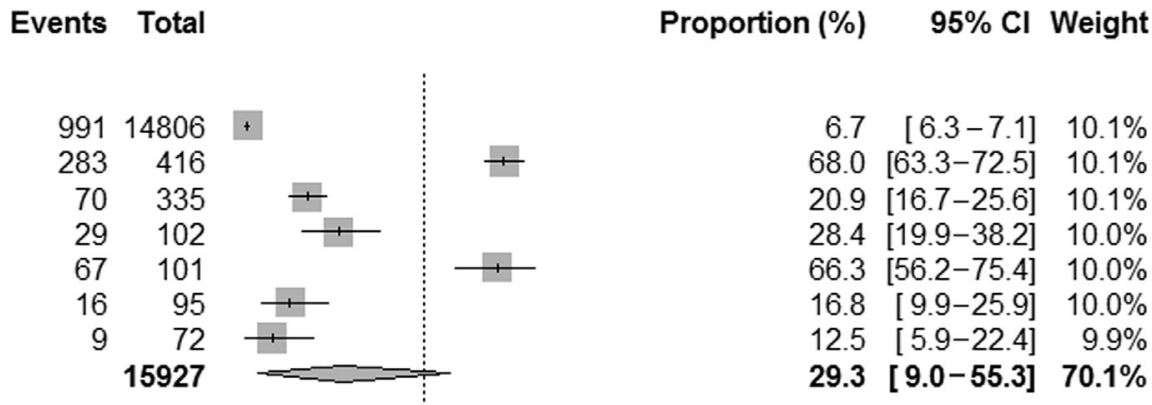

86.0 [80.7-90.3] $10.0 \%$

94.0 [88.8-97.2] $10.0 \%$

$21.8[13.7-32.0] \quad 0.0 \%$

89.3 [78.1-96.0] $9.9 \%$

90.0 [83.8-94.9] $29.9 \%$

$48.9[21.4-76.7] 100.0 \%$

16440

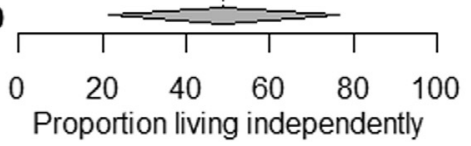

Fig 2 Continued.

scarce, addressing only $5 \%$ of the included studies. ${ }^{6}$ Notably, most of the included studies were conducted in North America, Western Europe, Asia, or Australia (see table 1), limiting generalizability of the results to other regions, for example, those with lower resources. Because of limited availability of population-based studies (eg, registry studies) ${ }^{15}$ in adults with CP compared with children, we were unable to restrict the selection of articles to populationbased samples, causing substantial variability in severity of motor and intellectual disability between samples (see table 1). However, the total of all study samples included is considered representative for the population of adults with $\mathrm{CP}$ with the majority male and with GMFCS I-III and including both mixed and no ID samples. The mean age of samples was 32 years, indicating the included articles mainly studied younger adults, and the results may not be applicable to older adults with CP. Note that we excluded nonrepresentative samples that were specifically selected 
in original studies on having a certain impairment. Still, by including all representative study samples with at least 25 adults with $\mathrm{CP}$ who were relatively representative of (a subgroup of) the population with $\mathrm{CP}$, we provided the best available knowledge on the most often studied outcomes in adults with CP. Another limitation of the study may be that we only focused on results that were reported as outcomes in the original studies, in line with the review on most studied outcomes of Benner et al, ${ }^{6}$ thus not including information that was originally reported on as sample characteristics, such as level of gross motor functioning, educational level, or employment status.

\section{Conclusions}

The present systematic review and meta-analysis provided stateof-the-art knowledge of the epidemiology of the most studied outcomes of health status, impairments, activities, and participation in adults with CP. Epilepsy and asthma are comorbidities that occur often in adults with CP. Overall, a majority of adults with $\mathrm{CP}$ experience pain, and on average adults with $\mathrm{CP}$ are fatigued. A majority of adults with $\mathrm{CP}$ are ambulant and have little or no difficulty in manual ability. A minority of the total population are employed or live independently, with much higher proportions living independently for individuals without ID. More uniformity in assessment and reporting is advised to enable more specified data synthesis on a wider range of outcomes.

\section{Supplier}

a. R 3.2.5; R Foundation for Statistical Computing.

\section{Keywords}

Adult; Cerebral palsy; Epidemiology; Health; Meta-analysis; Rehabilitation; Systematic review

\section{Corresponding author}

Marij E. Roebroeck, PhD, Erasmus MC University Medical Center, Dept of Rehabilitation Medicine, PO Box 2040, 3000 CA Rotterdam, The Netherlands. E-mail address: m.roebroeck@ erasmusmc.nl.

\section{Acknowledgment}

We thank Wichor Bramer, PhD, for Rijndam Rehabilitation, Rotterdam his support in developing and conducting the literature search.

\section{References}

1. Rosenbaum P, Paneth N, Leviton A, et al. A report: the definition and classification of cerebral palsy April 2006. Dev Med Child Neurol Suppl 2007;109:8-14.
2. Odding E, Roebroeck ME, Stam HJ. The epidemiology of cerebral palsy: incidence, impairments and risk factors. Disabil Rehabil 2006; 28:183-91.

3. Paneth N, Hong T, Korzeniewski S. The descriptive epidemiology of cerebral palsy. Clin Perinatol 2006;33:251-67.

4. Maenner MJ, Blumberg SJ, Kogan MD, Christensen D, YearginAllsopp M, Schieve LA. Prevalence of cerebral palsy and intellectual disability among children identified in two U.S. National Surveys, 2011-2013. Ann Epidemiol 2016;26:222-6.

5. Access Economics. The economic impact of cerebral palsy in Australia in 2007. Canberra: Access Economics; 2008.

6. Benner JL, Noten S, Limsakul C, et al. Outcomes in adults with cerebral palsy: systematic review using the International Classification of Functioning, Disability and Health. Dev Med Child Neurol 2019;61:1153-61.

7. Fortuna RJ, Holub A, Turk MA, Meccarello J, Davidson PW. Health conditions, functional status and health care utilization in adults with cerebral palsy. Fam Pract 2018;35:661-70.

8. Whitney DG, Hurvitz EA, Ryan JM, et al. Noncommunicable disease and multimorbidity in young adults with cerebral palsy. Clin Epidemiol 2018;10:511-9.

9. Turk MA, Logan LR, Ansoanuur F. Adults with childhood onset disabilities: a focused review of three conditions. Curr Phys Med Rehabil Rep 2013;1:72-87.

10. Benner JL, Hilberink SR, Veenis T, Stam HJ, van der Slot WM, Roebroeck ME. Long-term deterioration of perceived health and functioning in adults with cerebral palsy. Arch Phys Med Rehabil 2017;98:2196-205.

11. Opheim A, Jahnsen R, Olsson E, Stanghelle JK. Walking function, pain, and fatigue in adults with cerebral palsy: a 7-year follow-up study. Dev Med Child Neurol 2009;51:381-8.

12. Benner JL, Hilberink SR, Veenis $\mathrm{T}$, van der Slot WMA, Roebroeck ME. Course of employment in adults with cerebral palsy over a 14-year period. Dev Med Child Neurol 2017;59:762-8.

13. Schmidt AK, Van Gorp M, Van Wely L, et al. Autonomy in participation in cerebral palsy from chidhood to adulthood. Dev Med Child Neurol 2020;62:363-71.

14. van Gorp M, Van Wely L, Dallmeijer AJ, et al. Long-term course of difficulty in participation of individuals with cerebral palsy aged 16 to 34 years: a prospective cohort study. Dev Med Child Neurol 2019; 61:194-203.

15. Novak I, Hines M, Goldsmith S, Barclay R. Clinical prognostic messages from a systematic review on cerebral palsy. Pediatrics 2012;130:e1285-312.

16. Jonsson U, Eek MN, Sunnerhagen KS, Himmelmann K. Cerebral palsy prevalence, subtypes, and associated impairments: a population-based comparison study of adults and children. Dev Med Child Neurol 2019;61:1162-7.

17. WHO International. Classification of Functioning, Disability and Health. Geneva: ICF; 2001.

18. Ballester-Plane J, Laporta-Hoyos O, Macaya A, et al. Cognitive functioning in dyskinetic cerebral palsy: its relation to motor function, communication and epilepsy. Eur J Paediatr Neurol 2018;22:102-12.

19. Laporta-Hoyos O, Fiori S, Pannek K, et al. Brain lesion scores obtained using a simple semi-quantitative scale from MR imaging are associated with motor function, communication and cognition in dyskinetic cerebral palsy. Neuroimage Clin 2018;19:892-900.

20. Whitney DG, Hurvitz EA, Devlin MJ, et al. Age trajectories of musculoskeletal morbidities in adults with cerebral palsy. Bone 2018; 114:285-91.

21. Cremer N, Hurvitz EA, Peterson MD. Multimorbidity in middle-aged adults with cerebral palsy. Am J Med 2017;130:744.

22. Agustsson A, Sveinsson T, Pope P, Rodby-Bousquet E. Preferred posture in lying and its association with scoliosis and windswept hips in adults with cerebral palsy. Disabil Rehabil 2019;41:3198-202.

23. Alriksson-Schmidt A, Hagglund G, Rodby-Bousquet E, Westbom L. Follow-up of individuals with cerebral palsy through the transition 
years and description of adult life: the Swedish experience. J Pediatr Rehabil Med 2014;7:53-61.

24. Rodby-Bousquet E, Czuba T, Hagglund G, Westbom L. Postural asymmetries in young adults with cerebral palsy. Dev Med Child Neurol 2013;55:1009-15.

25. van Gorp M, Roebroeck ME, Swan Tan S, et al. Activity performance curves of individuals with cerebral palsy. Pediatrics 2018;142.

26. van Meeteren J, Nieuwenhuijsen C, de Grund A, Stam HJ, Roebroeck ME; Transition Research Group South West Netherlands. Using the manual ability classification system in young adults with cerebral palsy and normal intelligence. Disabil Rehabil 2010;32: 1885-93.

27. Nieuwenhuijsen C, Donkervoort M, Nieuwstraten W, Stam HJ, Roebroeck ME; Transition Research Group South West Netherlands. Experienced problems of young adults with cerebral palsy: targets for rehabilitation care. Arch Phys Med Rehabil 2009;90:1891-7.

28. van der Dussen L, Nieuwstraten W, Roebroeck M, Stam HJ. Functional level of young adults with cerebral palsy. Clin Rehabil 2001; 15:84-91.

29. Kirk H, Geertsen SS, Lorentzen J, Krarup KB, Bandholm T, Nielsen JB. Explosive resistance training increases rate of force development in ankle dorsiflexors and gait function in adults with cerebral palsy. J Strength Cond Res 2016;30:2749-60.

30. McPhee PG, Gorter JW, Cotie LM, Timmons BW, Bentley T, MacDonald MJ. Descriptive data on cardiovascular and metabolic risk factors in ambulatory and non-ambulatory adults with cerebral palsy. Data Brief 2015;5:967-70.

31. McPhee PG, Gorter JW, Cotie LM, Timmons BW, Bentley T, MacDonald MJ. Associations of non-invasive measures of arterial structure and function, and traditional indicators of cardiovascular risk in adults with cerebral palsy. Atherosclerosis 2015;243:462-5.

32. Slaman J, van den Berg-Emons HJ, van Meeteren J, et al. A lifestyle intervention improves fatigue, mental health and social support among adolescents and young adults with cerebral palsy: focus on mediating effects. Clin Rehabil 2015;29:717-27.

33. Russchen HA, Slaman J, Stam HJ, et al. Focus on fatigue amongst young adults with spastic cerebral palsy. J Neuroeng Rehabil 2014; 11:161.

34. Slaman J, Roebroeck M, van der Slot W, et al. Can a lifestyle intervention improve physical fitness in adolescents and young adults with spastic cerebral palsy? A randomized controlled trial. Arch Phys Med Rehabil 2014;95:1646-55.

35. Ryan JM, Crowley VE, Hensey O, McGahey A, Gormley J. Waist circumference provides an indication of numerous cardiometabolic risk factors in adults with cerebral palsy. Arch Phys Med Rehabil 2014;95:1540-6.

36. Morgan PE, Soh SE, McGinley JL. Health-related quality of life of ambulant adults with cerebral palsy and its association with falls and mobility decline: a preliminary cross sectional study. Health Qual Life Outcomes 2014;12:132.

37. Morgan P, McGinley J. Performance of adults with cerebral palsy related to falls, balance and function: a preliminary report. Dev Neurorehabil 2013;16:113-20.

38. Reddihough DS, Jiang B, Lanigan A, Reid SM, Walstab JE, Davis E. Social outcomes of young adults with cerebral palsy. J Intellect Dev Disabil 2013;38:215-22.

39. van der Slot WM, Roebroeck ME, Nieuwenhuijsen C, et al. Cardiovascular disease risk in adults with spastic bilateral cerebral palsy. J Rehabil Med 2013;45:866-72.

40. van der Slot WM, Nieuwenhuijsen C, van Den Berg-Emons RJ, et al. Chronic pain, fatigue, and depressive symptoms in adults with spastic bilateral cerebral palsy. Dev Med Child Neurol 2012;54:836-42.

41. van der Slot WM, Nieuwenhuijsen C, van den Berg-Emons RJ, et al. Participation and health-related quality of life in adults with spastic bilateral cerebral palsy and the role of self-efficacy. J Rehabil Med 2010;42:528-35.
42. Opheim A, Jahnsen R, Olsson E, Stanghelle JK. Physical and mental components of health-related quality of life and musculoskeletal pain sites over seven years in adults with spastic cerebral palsy. J Rehabil Med 2011;43:382-7.

43. Jahnsen R, Villien L, Egeland T, Stanghelle JK, Holm I. Locomotion skills in adults with cerebral palsy. Clin Rehabil 2004;18: 309-16.

44. Jahnsen R, Villien L, Aamodt G, Stanghelle JK, Holm I. Musculoskeletal pain in adults with cerebral palsy compared with the general population. J Rehabil Med 2004;36:78-84.

45. Jahnsen R, Villien L, Stanghelle JK, Holm I. Coping potential and disability-sense of coherence in adults with cerebral palsy. Disabil Rehabil 2002;24:511-8.

46. Maltais DB, Dumas F, Boucher N, Richards CL. Factors related to physical activity in adults with cerebral palsy may differ for walkers and nonwalkers. Am J Phys Med Rehabil 2010;89:584-97.

47. Michelsen SI, Uldall P, Hansen T, Madsen M. Social integration of adults with cerebral palsy. Dev Med Child Neurol 2006;48:643-9.

48. Michelsen SI, Uldall P, Kejs AM, Madsen M. Education and employment prospects in cerebral palsy. Dev Med Child Neurol 2005;47:511-7.

49. Engel JM, Jensen MP, Hoffman AJ, Kartin D. Pain in persons with cerebral palsy: extension and cross validation. Arch Phys Med Rehabil 2003;84:1125-8.

50. Gillett JG, Lichtwark GA, Boyd RN, Barber LA. Functional capacity in adults with cerebral palsy: lower limb muscle strength matters. Arch Phys Med Rehabil 2018;99:900-6.

51. Lundh S, Nasic S, Riad J. Fatigue, quality of life and walking ability in adults with cerebral palsy. Gait Posture 2018;61:1-6.

52. Park MW, Kim WS, Bang MS, et al. Needs for medical and rehabilitation services in adults with cerebral palsy in Korea. Ann Rehabil Med 2018;42:465-72.

53. Peterson MD, Kamdar N, Hurvitz EA. Age-related trends in cardiometabolic disease among adults with cerebral palsy. Dev Med Child Neurol 2019;61:484-9.

54. Sienko SE. An exploratory study investigating the multidimensional factors impacting the health and well-being of young adults with cerebral palsy. Disabil Rehabil 2018;40:660-6.

55. Smith KJ, Peterson MD, O'Connell NE, et al. Risk of depression and anxiety in adults with cerebral palsy. JAMA Neurol 2019;76:294300.

56. Daunter AK, Kratz AL, Hurvitz EA. Long-term impact of childhood selective dorsal rhizotomy on pain, fatigue, and function: a casecontrol study. Dev Med Child Neurol 2017;59:1089-95.

57. de Albuquerque Botura C, Ames FQ, de Albuquerque Botura AC, Bersani-Amado LE, Bardini AVSL, Cuman RKN. Pain symptoms in patients with severe cerebral palsy: prevalence among patients with higher degree of locomotor impairment. Trop J Pharm Res 2017;16: 1431-6.

58. Hayward K, Chen AY, Forbes E, Byrne R, Greenberg MB, Fowler EG. Reproductive healthcare experiences of women with cerebral palsy. Disabil Health J 2017;10:413-8.

59. Park EY, Kim WH. Prevalence of secondary impairments of adults with cerebral palsy according to gross motor function classification system. J Phys Ther Sci 2017;29:266-9.

60. Vukojević M, Cvitković T, Splavski B, Ostojić Z, ŠumanovićGlamuzina D, Šimić J. Prevalence of intellectual disabilities and epilepsy in different forms of spastic cerebral palsy in adults. Psychiatr Danub 2017;29:111-7.

61. Yıldız N, Akkoç Y, Ersöz M, et al. Cross-sectional study of urinary problems in adults with cerebral palsy: awareness and impact on the quality of life. Neurol Sci 2017;38:1193-203.

62. Brunton L, Hall S, Passingham A, Wulff J, Delitala R. The prevalence, location, severity, and daily impact of pain reported by youth and young adults with cerebral palsy. J Pediatr Rehabil Med 2016;9: 177-83.

63. Peterson MD, Ryan JM, Hurvitz EA, Mahmoudi E. Chronic conditions in adults with cerebral palsy. JAMA 2015:314:2303-5. 
64. Peterson MD, Haapala HJ, Chaddha A, Hurvitz EA. Abdominal obesity is an independent predictor of serum 25-hydroxyvitamin D deficiency in adults with cerebral palsy. Nutr Metab (Lond) 2014;11:22.

65. Huang IC, Wang YT, Chan F. Employment outcomes of adults with cerebral palsy in Taiwan. Disabil Rehabil 2013;35:228-35.

66. Hamrah Nedjad J, Jansson E, Bartonek A. Physical activity in a swedish youth and adult population with cerebral palsy. Eur J Physiother 2013;15:70-7.

67. Mesterman R, Leitner Y, Yifat R, et al. Cerebral palsy-long-term medical, functional, educational, and psychosocial outcomes. J Child Neurol 2010;25:36-42.

68. Gaskin CJ, Morris T. Physical activity, health-related quality of life, and psychosocial functioning of adults with cerebral palsy. J Phys Act Health 2008;5:146-57.

69. Andersson C, Asztalos L, Mattsson E. Six-minute walk test in adults with cerebral palsy. A study of reliability. Clin Rehabil 2006;20:488-95.

70. Sandström K, Alinder J, Öberg B. Descriptions of functioning and health and relations to a gross motor classification in adults with cerebral palsy. Disabil Rehabil 2004;26:1023-31.

71. Strauss D, Ojdana K, Shavelle R, Rosenbloom L. Decline in function and life expectancy of older persons with cerebral palsy. NeuroRehabilitation 2004;19:69-78.

72. Andersson C, Mattsson E. Adults with cerebral palsy: a survey describing problems, needs, and resources, with special emphasis on locomotion. Dev Med Child Neurol 2001;43:76-82.

73. Bottos M, Feliciangeli A, Sciuto L, Gericke C, Vianello A. Functional status of adults with cerebral palsy and implications for treatment of children. Dev Med Child Neurol 2001;43:516-28.

74. Furukawa A, Iwatsuki H, Nishiyama M, Nii E, Uchida A. A study on the subjective well-being of adult patients with cerebral palsy. J Phys Ther Sci 2001;13:31-5.

75. Hodgkinson I, Jindrich ML, Duhaut P, Vadot JP, Metton G, Bérard C. Hip pain in 234 non-ambulatory adolescents and young adults with cerebral palsy: a cross-sectional multicentre study. Dev Med Child Neurol 2001;43:806-8.

76. Maruishi M, Mano Y, Sasaki T, Shinmyo N, Sato H, Ogawa T. Cerebral palsy in adults: independent effects of muscle strength and muscle tone. Arch Phys Med Rehabil 2001;82:637-41.

77. Murphy KPM, Molnar GE, Lankasky K. Employment and social issues in adults with cerebral palsy. Arch Phys Med Rehabil 2000;81: 807-11.

78. Aaronson NK, Muller M, Cohen PD, et al. Translation, validation, and norming of the Dutch language version of the SF-36 Health Survey in community and chronic disease populations. J Clin Epidemiol 1998;51:1055-68.

79. Krupp LB, LaRocca NG, Muir-Nash J, Steinberg AD. The fatigue severity scale. Application to patients with multiple sclerosis and systemic lupus erythematosus. Arch Neurol 1989;46:1121-3.

80. Eliasson AC, Krumlinde-Sundholm L, Rosblad B, et al. The Manual Ability Classification System (MACS) for children with cerebral palsy: scale development and evidence of validity and reliability. Dev Med Child Neurol 2006;48:549-54.

81. UNESCO Institute for Statistics. International Standard Classification of Education (ISCED) 2011. Montreal: UNESCO Institute for Statistics; 2012.

82. Lemmens J, van Engelen EISM, Post MWM, Beurskens AJHM, Wolters PMJC, de Witte LP. Reproducibility and validity of the Dutch Life Habits Questionnaire (LIFE-H 3.0) in older adults. Clin Rehabil 2007;21:853-62.

83. Collin C, Wade DT, Davies S, Horne V. The Barthel ADL Index: a reliability study. Int Disabil Stud 1988;10:61-3.

84. Linacre JM, Heinemann AW, Wright BD, Granger CV, Hamilton BB. The structure and stability of the Functional Independence Measure. Arch Phys Med Rehabil 1994;75:127-32.

85. Russell DJ, Rosenbaum PL, Cadman DT, Gowland C, Hardy S, Jarvis S. The gross motor function measure: a means to evaluate the effects of physical therapy. Dev Med Child Neurol 1989;31:341-52.
86. Graham HK, Harvey A, Rodda J, Nattrass GR, Pirpiris M. The Functional Mobility Scale (FMS). J Pediatr Orthop 2004;24:514-20.

87. Izumida S, Inoue S. Assessment of treatment for low back pain. J Jpn Orthop Assoc 1986;60:391-4.

88. Palisano RJ, Hanna SE, Rosenbaum PL, Russell DJ, Walter SD, Wood EP, et al. Validation of a model of gross motor function for children with cerebral palsy. Phys Ther 2000;80:974-85.

89. DerSimonian R, Laird N. Meta-analysis in clinical trials. Control Clin Trials 1986;7:177-88.

90. Freeman MF, Tukey JW. Transformations related to the angular and the square root. The Ann Math Stat 1950;21:607-11.

91. Miller JJ. The inverse of the Freeman-Tukey double arcsine transformation. Am Stat 1978;32:138.

92. Higgins JP, Thompson SG, Deeks JJ, Altman DG. Measuring inconsistency in meta-analyses. BMJ 2003;327:557-60.

93. Himmelmann K, Beckung E, Hagberg G, Uvebrant P. Gross and fine motor function and accompanying impairments in cerebral palsy. Dev Med Child Neurol 2006;48:417-23.

94. To T, Stanojevic S, Moores G, et al. Global asthma prevalence in adults: findings from the cross-sectional world health survey. BMC Public Health 2012;12:204.

95. van der Slot W, Benner J, Brunton L, et al. Pain in adults with cerebral palsy: a systematic review and meta-analysis of individual participant data. Ann Phys Med Rehabil 2020 Feb 13 [Epub ahead of print].

96. Nahin RL. Estimates of pain prevalence and severity in adults: United States, 2012. J Pain 2015;16:769-80.

97. Valko PO, Bassetti CL, Bloch KE, Held U, Baumann CR. Validation of the fatigue severity scale in a Swiss cohort. Sleep 2008;31:1601-7.

98. Gross PH, Bailes AF, Horn SD, et al. Setting a patient-centered research agenda for cerebral palsy: a participatory action research initiative. Dev Med Child Neurol 2018;60:1278-84.

99. Vogtle LK. Pain in adults with cerebral palsy: impact and solutions. Dev Med Child Neurol 2009;51(Suppl 4):113-21.

100. Brunton LK, McPhee PG, Gorter JW. Self-reported factors contributing to fatigue and its management in adolescents and adults with cerebral palsy. Disabil Rehabil 2019;30(Jul):1-7.

101. Carnahan KD, Arner M, Hagglund G. Association between gross motor function (GMFCS) and manual ability (MACS) in children with cerebral palsy. A population-based study of 359 children. BMC Musculoskelet Disord 2007;8:50.

102. Langerak NG, Hillier SL, Verkoeijen PP, Peter JC, Fieggen AG, Vaughan CL. Level of activity and participation in adults with spastic diplegia 17-26 years after selective dorsal rhizotomy. J Rehabil Med 2011:43:330-7.

103. Donkervoort M, Roebroeck M, Wiegerink D, van der HeijdenMaessen H, Stam H. Determinants of functioning of adolescents and young adults with cerebral palsy. Disabil Rehabil 2007;29: 453-63.

104. Jacobsen EL, Bye A, Aass N, et al. Norwegian reference values for the Short-Form Health Survey 36: development over time. Qual Life Res 2018;27:1201-12.

105. Surveillance of Cerebral Palsy in Europe. Surveillance of cerebral palsy in Europe: a collaboration of cerebral palsy surveys and registers. Surveillance of Cerebral Palsy in Europe (SCPE). Dev Med Child Neurol 2000;42:816-24.

106. Hurley DS, Sukal-Moulton T, Msall ME, Gaebler-Spira D, Krosschell KJ, Dewald JP. The cerebral palsy research registry: development and progress toward national collaboration in the United States. J Child Neurol 2011;26:1534-41.

107. McPhee PG, Benner JL, Balemans ACJ, et al. Multimorbidity risk assessment in adolescents and adults with cerebral palsy: a protocol for establishing a core outcome set for clinical research and practice. Trials 2019;20:176.

108. Maulik PK, Mascarenhas MN, Mathers CD, Dua T, Saxena S. Prevalence of intellectual disability: a meta-analysis of populationbased studies. Res Dev Disabil 2011;32:419-36. 